\title{
4
}

\section{Modeling Every Sanitary Pipe in the City: Unique Aspects and Benefits}

\author{
Marc C. Stonehouse, Benjamin J. Sherman, Pete P. Perala, \\ David Wilburn, Mark J. TenBroek, and Henry P. Fan
}

As part of an effort to better manage SSOs and basement backups, the City of Ann Arbor developed a citywide model that includes all of the approximately 11,000 sanitary sewer pipes in their collection system. The model developed was based on the US EPA SWMM 4.4h engine and uses the Rainfall Dependent Inflow and Infiltration (RDII) parameters. This chapter addresses the following key issues associated with this work.

- To accommodate the size of the model input, certain parameter arrays were increased from that currently available in $4.4 \mathrm{~h}$ versions. It was found that optimizing model settings and the computers used to run the model allowed for entire citywide simulations to be run in three to five hours, eliminating the need for multiple area models.

- Use of high quality geographic information system (GIS) and global positioning system (GPS) information allowed for quick and efficient model development.

- The model uses over 2,600 sub-basins to provide the resolution needed to support the footing drain disconnection program effectively. Further, this resolution reduced dependence on hydrologic parameters to account

Stonehouse, M.C., B.J. Sherman, P.P. Perala, D. Wilburn, M.J. TenBroek and H. Fan. 2006. "Modeling Every Sanitary Pipe in a City: Unique Aspects and Benefits." Journal of Water Management Modeling R225-04. doi: 10.14796/JWMM.R225-04.

(C) CHI 2006 www.chijournal.org ISSN: 2292-6062 (Formerly in Intelligent Modeling of Urban Water Systems. ISBN: 0-9736716-2-9) 
for routing i.e., the hydraulic model was better utilized to simulate routing than if fewer and larger subbasins were used.

- Field data collection included over 80 flow and peak level recorders coupled with radar rainfall distributed data.

- A distinct difference in system response was identified between the dormant (winter and early spring) and growth (summer and early fall) seasons.

- To facilitate the use of the high number of sub-basins, GIS information, including soil types, percent impervious, surface water features, age of construction, and ground slopes were used to allocate wet weather parameters.

- The water use records were linked to the parcel layer to compare dry weather flows (DWF) to flow meter data and to allocate dry weather I/I distinct from sanitary usage.

- During calibration, one of the key findings was that shape parameters could be grouped by footing drain and non-footing drain areas and the average size of the sub-basin so that ultimately, only 6 different shape parameter groupings were required to match modeled peak and volume to observed data.

Overall, the city has found the investment into this size of a model to be beneficial as the model is being used to facilitate prioritization of the footing drain disconnection program to maximize removal of footing drain flows and gain the most benefit for relieving system deficiencies and basement flooding. The model is also being used to evaluate newly proposed development projects. This includes analysis of available capacity, best locations for footing drain mitigation to offset new development, and reviewing alternatives for system upgrades to allow for development where footing drain disconnection cannot mitigate system problems.

\subsection{Introduction}

As part of an effort to better manage SSOs and basement backups, the City of Ann Arbor developed a citywide model that includes all of the approximately 11,000 sanitary sewer pipes in their collection system. The model developed was based on the US EPA SWMM 4.4h engine and uses the RDII parameters.

The model was used to determine how the sanitary collection system responds to storm scenarios of differing intensities, and to understand how 
the City's ongoing Footing Drain Disconnection (FDD) Program will affect the system during these storms (Sanitary Sewer Overflow Study Task Force; Sherman et al.; Sherman et al.; Zawacki et al.). This analysis helped improve the City's understanding of specific deficiencies in its collection system so that corrections can be planned for and made to ensure consistent service for all customers.

Moreover, the citywide model of Ann Arbor's sanitary sewer system provides staff with an ongoing planning tool that can be used to evaluate sewer service for new development in the City, the impact of such development on the existing system and its customers, and effective strategies for continued compliance with environmental regulations and policies.

\subsection{Base Information and Evaluation}

\subsubsection{Sanitary Sewer System GIS Development}

One of the initial project tasks was to collect, verify, organize, and digitize information on the geographic layout and physical attributes of the entire sanitary collection system. This task required the analysis of a variety of data sources, including the system index maps and infrastructure databases created by the city in the 1980s and 1990s. The data was used to prepare a draft GIS.

The draft GIS was then used to find the system's manholes. Once located in the field, the coordinates of each manhole were recorded using GPS equipment. During these field visits, the condition of each sewer segment was checked, and information on damage or design modifications was used to update the draft GIS. A final GIS was created based on this information, later field checks, and sewer drawings. Omnistar real-time correction was used for the GPS data. It was determined that $98.7 \%$ of the GPS data is within $+/-5$ feet accuracy based on multiple daily checks against survey benchmarks.

Attribute information, such as pipe diameter, elevations, and pipe materials, was previously created by the city for each feature using as-built drawings. Basic checks of this database were made and field inspections were used when questionable information was found. 


\subsubsection{Flow and Level Data Collection}

The monitoring program included 40 sanitary flow metering locations throughout the City, resulting on average in one flow meter for approximately each square mile. Several flow meters were located in the trunk sewer system to estimate responses from larger areas and ensure that flows balanced from one district to the next. Other flow meters were placed strategically to help understand critical flow paths and system responses.

In addition to the data from the meters, the project team collected flow data at the Ann Arbor waste water treatment plant (WWTP) and from six pump stations throughout the city.

As data were collected, the project team identified potentially poor quality data. The team also reviewed weekly plots of the data generated by each meter. Further, long-term plots of the flow, level, and velocity data were used to identify changes in meter operation not evident in weekly plots.

Where applicable, data initially identified as poor quality were corrected using either a constant level offset or Manning's equation. Level corrections were based on biweekly field measurement checks. In many cases, these checks found level sensor errors that could be corrected. Once the level data was corrected, the resulting flow data could be recalculated. Overall, approximately 86 percent of the flow data collected were accepted for use.

For periods of poor quality velocity sensor data, flow-versus-level plots were used to develop a Manning's flow relationship for each meter. The flow was then recalculated based on the available level data.

Forty peak-stage recorders were also installed as part of the network. The peak-stage recorders were constructed of PVC. Wooden staff gauges and floating cork are used inside the PVC tube to indicate the highest water level since the previous measurement. Placed in locations suspected of sanitary sewer overflows, basement flooding, and system constraints, these devices provided information on the stage level after significant rains. The peakstage recorders were checked five times during the project.

\subsubsection{Rainfall Data Collection}

Five rain gauges were installed by the team. In addition, data from five existing rain gauges was gathered during the monitoring period. Unfortunately, no rainfall events over 2 in were monitored. Therefore, the computer model was calibrated using events with significantly lower total rainfall than those later simulated (greater than 3.4 in). 


\subsubsection{Data Evaluation}

\subsubsection{Radar Rainfall Analysis}

Radar data for the project area were purchased from a commercial vendor, OneRain, Inc. (formerly NexRAIN). It was provided at a $1 \mathrm{~km}$ x $1 \mathrm{~km}$ resolution. A grid representing the $1 \mathrm{~km} \times 1 \mathrm{~km}$ spatial units, called "pixels" by the vendor, was provided to the project team as a GIS layer. For example, Figure 4.1 shows the rainfall totals by pixel for the April 4, 2003 rainfall event. The six months of 2003 data recorded includes 30.5 million fiveminute records.

The project team used area weighting to break out rainfall data for each meter tributary area. It also prepared summary statistics for each rain event, including:

- start and stop date/times;

- sum of rainfall volume;

- percentage of records indicating rainfall;

- total number of records;

- $\quad$ peak five-minute intensity (in/h);

- peak one-hour intensity (in/h); and

- rainfall volumes for the two- and four-week periods before each event.

These statistics were then used to support RDII analysis.

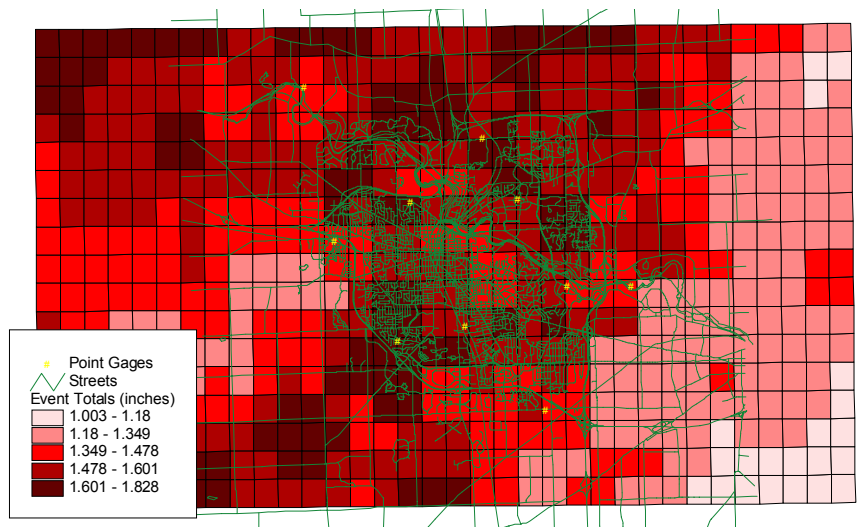

Figure $4.11 \mathrm{~km} \times 1 \mathrm{~km}$ radar rainfall for the April 4, 2003 rainfall event. 


\subsubsection{RDII Analysis}

A detailed protocol was used to develop event-specific RDII for each meter. This includes using the RDII shape and volume routines in RUNOFF, using typical combined area parameters for a reduced subbasin area to produce an inflow response, and using baseflow factors in EXTRAN or the groundwater routine in RUNOFF to produce an infiltration response. Regardless of methods used to model RDII, quantifying RDII can be performed by an even wider variety of methods, typically tailored to local conditions as no one method is universally applicable (Shultz et al.).

The RDII volume was calculated by subtracting the event-specific DWF from the hourly flow data. Where a second rainfall event occurred prior to completion of the previous event response, the first event response was projected to estimate the additional response that would have occurred if the second event had not occurred. The projected amount was added to the first event and subtracted from the second event RDII.

The event-specific RDII volumes were summarized in tables for each meter. A regression analysis was used to determine the average RDII response for the two distinct seasons, Dormant (winter) and Growth (summer). During the Growth season, which typically extends from midMay to mid-September in the Ann Arbor area, groundwater levels and soil moisture levels are reduced through evaporation. As moisture levels decline, so does the RDII response of sanitary systems to storms. RDII volumes for each season's set of data plotted against the total rainfall volumes identified a distinct transition date, as shown in Figure 4.2.

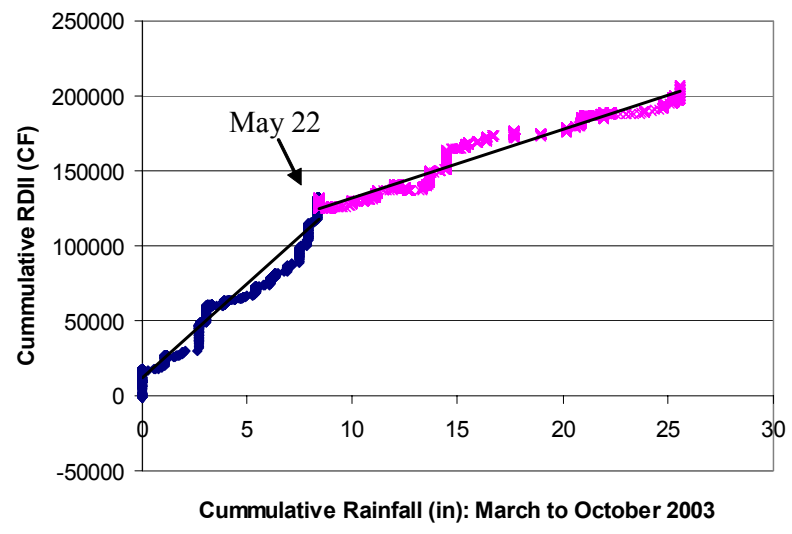

Figure 4.2 -Seasonal change in the system response. 
Plots of RDII volume versus rainfall were prepared for each season to determine the average capture coefficient $(\mathrm{R})$ by season for each meter. An example is given in Figure 4.3. In some cases, events are excluded because of higher-than-normal response caused by wet soil conditions from a previous event.

The average $\mathrm{R}$ capture coefficient is calculated for each meter and season as:

where:

$$
\mathrm{R}=\mathrm{SLOPE} / \mathrm{AREA}
$$

$$
\begin{aligned}
\mathrm{R} & =\text { capture coefficient }(\mathrm{in} / \mathrm{in}) \\
\text { SLOPE } & =\text { slope of regression line (cubic-feet/in) } \\
\text { AREA } & =\text { meter tributary area (square-feet) }
\end{aligned}
$$

The average $\mathrm{R}$ values are used in the model to represent both Dormant and Growth seasons.

The average $\mathrm{R}$ values include overlapping information for meter tributary areas with more than one downstream meter. Ideally, upstream and downstream meters could be used to calculate a single incremental $R$ value. However, due to the potential for large errors inherent in incremental calculations, each incremental area was reviewed independently for the best method to develop a single set of $\mathrm{R}$ values for each sub-basin in the model.

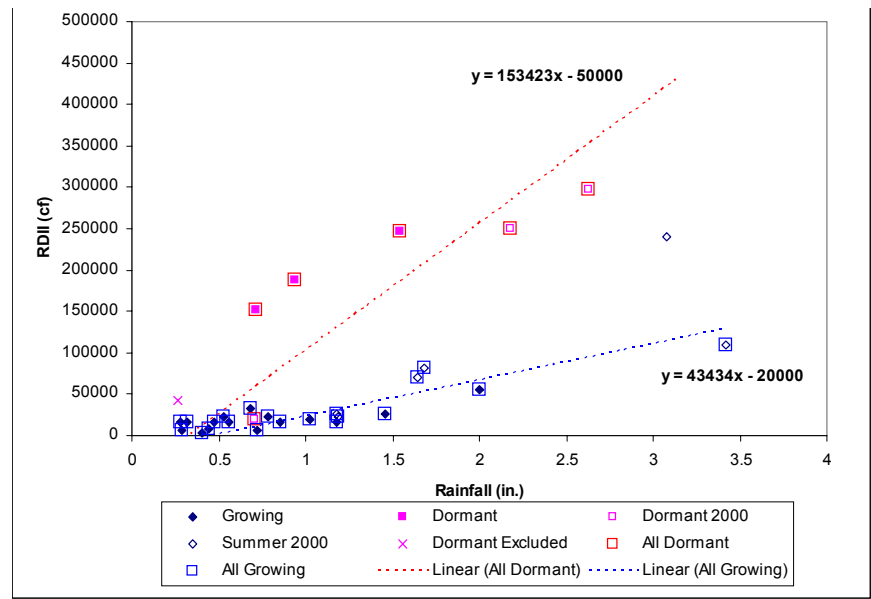

Figure 4.3 - Growth versus Dormant Season RDII response analysis. 
In unmetered areas, where poor meter data existed, or where incremental calculations were thought to include significant error, $\mathrm{R}$ value estimates were based on neighboring areas with similar characteristics.

RDII analysis areas were developed for the purpose of allocating RDII values. These areas are based on the incremental area between up and downstream meters as shown in Figure 4.4.

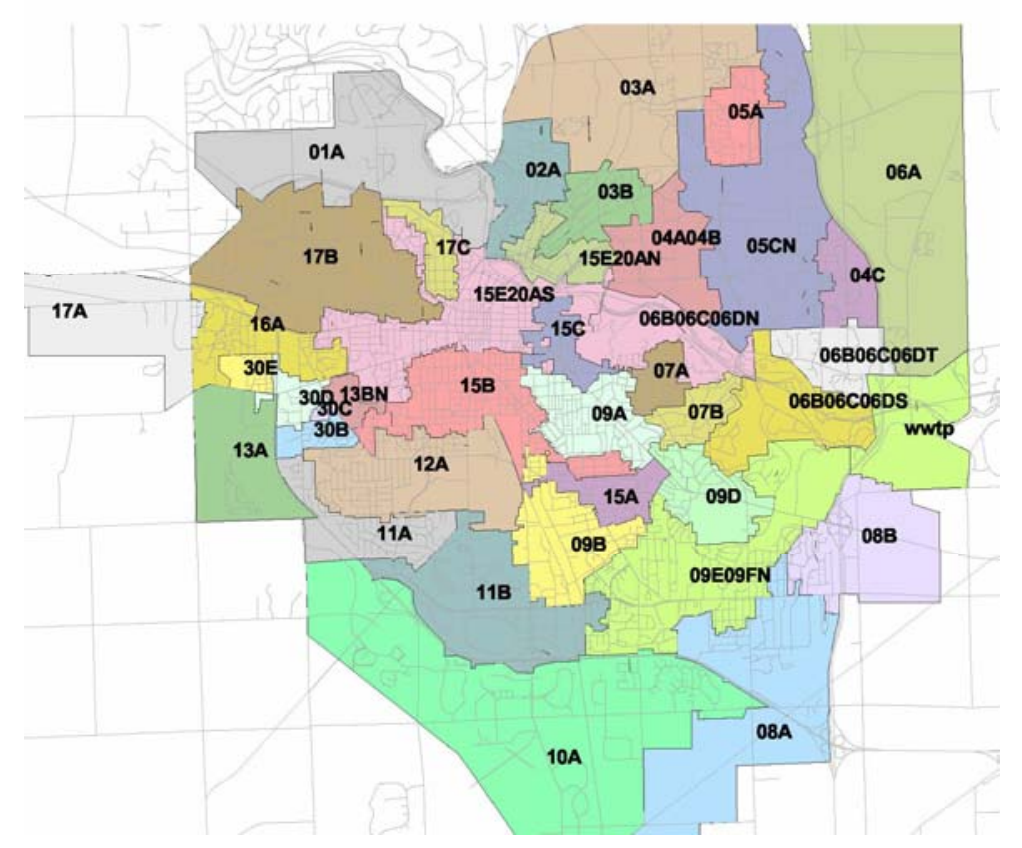

Figure 4.4 - Incremental RDII Analysis Areas

\subsubsection{GIS and Other Information}

GIS data sets along with other information were used to help understand reasons for variable dry and wet weather responses in the different RDII analysis areas. Some key analysis area characteristics that could affect or be related to RDII responses are:

- water use;

- number of connected footing drains; 
- $\quad$ soil type;

- sewer inch-miles;

- average age of construction;

- impervious ground; and

- water surfaces.

By comparing these characteristics to the system response, it was found that RDII was highest in areas with the greatest number of footing drains connected to the sanitary sewer system. Soil type also had an important influence on RDII volumes.

Based on the findings of thorough field investigations in one area of the city, it is likely that any type of structure with basements built before 1982 has footing drains connected to the sanitary sewer system. Using the results of a basement survey performed in that area, the number of equivalent single-family homes was estimated for the multifamily and commercial structures with and without basements. This was done as multifamily and commercial/industrial buildings are typically much larger than a singlefamily residence and the amount of footing drain inflow is expected to be related to its size (or more specifically the size of its footing drain).

The equivalent number calculated is based on the basement area divided by 1,200 square feet. The 1,200 square feet value is based on the average single-family house basement area that is being used by the City's footing drain disconnection program. As an example, a multifamily building having a basement that is 10 times the size (by area) of a typical single-family house basement is expected to have 10 times more footing drain inflow than a typical single-family house. Another alternative evaluated but not used is to use the average perimeter to calculate the equivalent number.

Multifamily and commercial/industrial basement areas are based on assessor database information. Where assessor information was not available, the estimate is based on roof area found using aerial photos. Based on a comparison between roof area estimates and assessor data, roof area estimates were reduced by $10 \%$ to account for garages, roof overhangs, and covered patios or staircases.

Figure 4.5 shows the total $\mathrm{R}$ values (capture coefficients) allocated throughout the city to over 2,600 sub-basins based on the monitoring results. Figure 4.6 shows the distribution and classification of equivalent footing drains (which include single-family equivalents for multifamily and commercial units) throughout the city in the over 2,600 sub-basins. These two figures show that footing drains built before 1942 do not appear to be as productive as those built after 1942, since areas built before 1942 have lower 
$\mathrm{R}$ values. These areas are primarily in the center of the city. It is suspected that these properties either do not have footing drains or the drains have since ceased to function adequately due to damage or plugging.

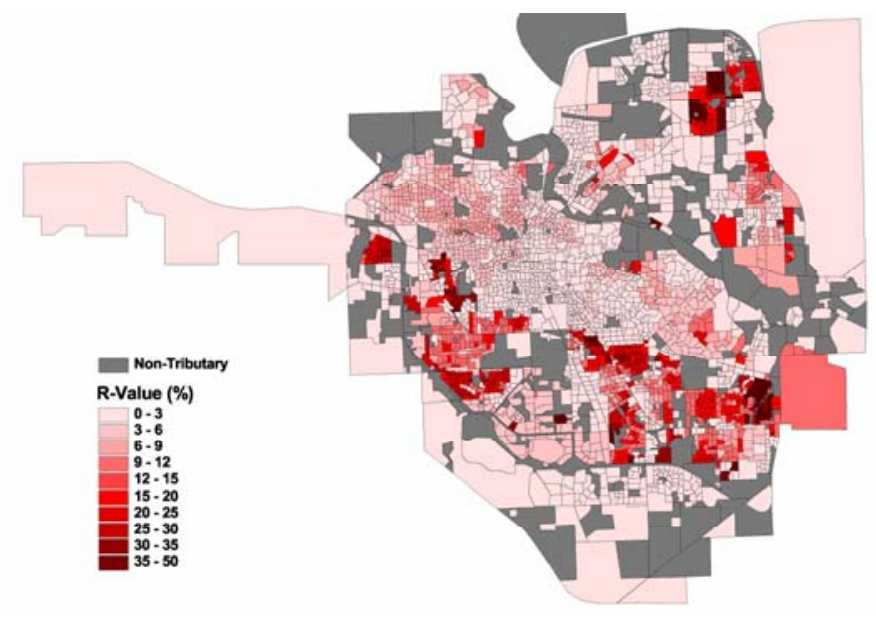

Figure 4.5 - Total $R$ value allocation.

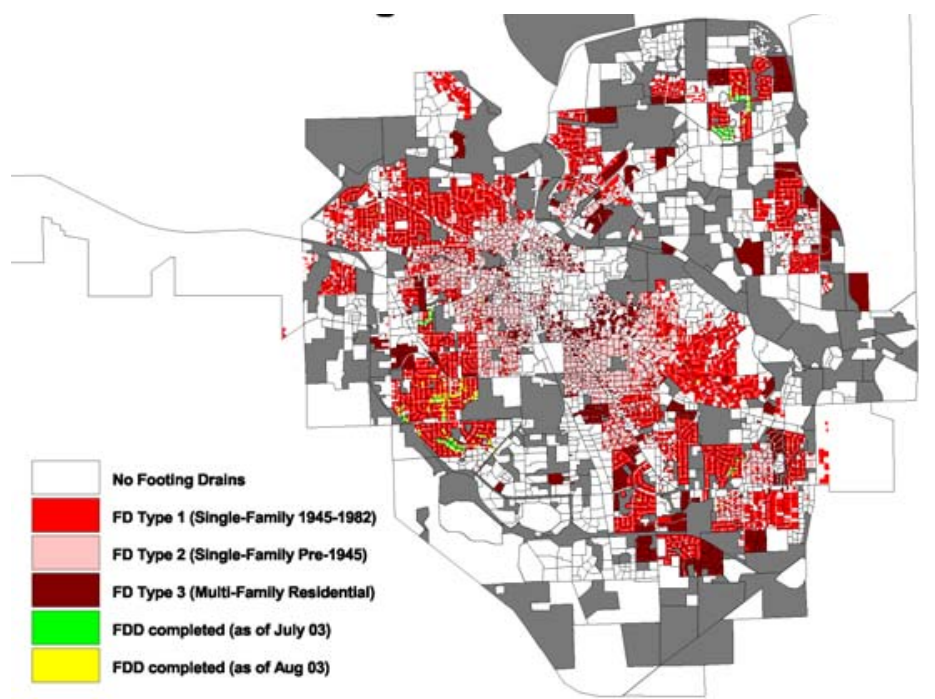

Figure 4.6 - Footing drain classifications. 


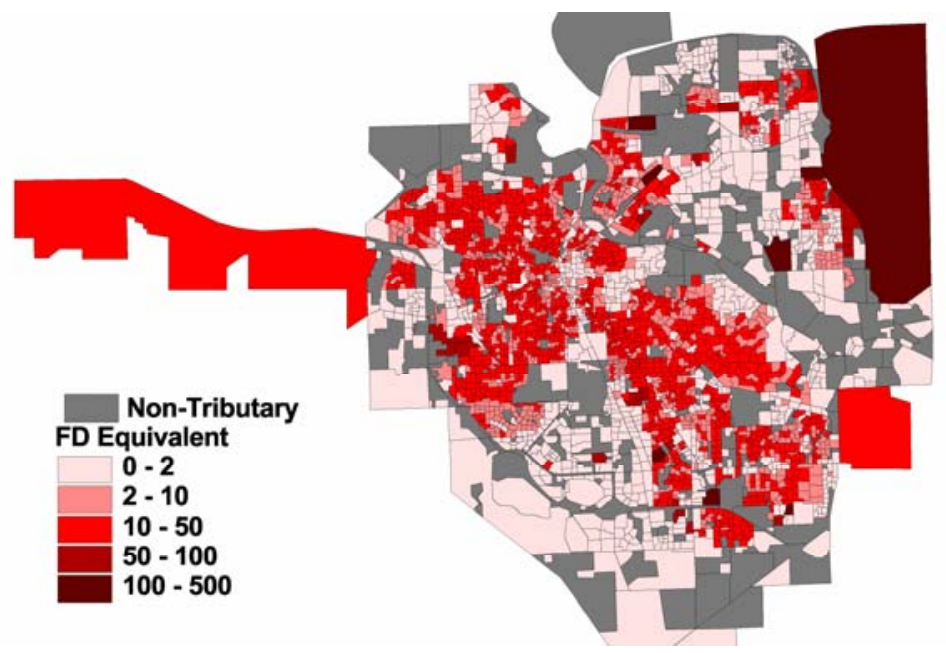

Figure 4.7 - Soil type distribution.

Within areas with footing drains, poorly drained soils such as clay demonstrated higher RDII responses than areas with well-drained soils, such as sand. This is likely due to poorly drained soils restricting infiltration to the groundwater, forcing surface water to move through less restrictive pathways such as toward structures and their foundation footing drains or the stormwater collection system. As shown in Figure 4.7, the poorly-drained C and D soil types are located primarily in the southern half of the city.

In the northern half of the city, the glacial moraine ends, leaving more well-drained soils. However, there are pockets of C and D soil types in the northern half, including just east of one of the primary basement flooding problem areas. Note that even though the soils map indicates A and B soil types in this problem area, fieldwork in this area indicates soils are actually $\mathrm{C}$ and $\mathrm{D}$ soil types. In general, the maps are accepted as correct, but may be off in this particular area.

Some areas with steeper slopes along the Huron River were found to have lower wet weather responses than expected, likely due to more rapid runoff to the surface drainage system. The other characteristics analyzed for these areas did not appear to be related to the amount of RDII. The expected RDII relationships for these characteristics may still be present in these areas, but could be hidden by the stronger presence of footing drains and soil types. 


\subsection{Model Development}

\subsubsection{Conceptual Model and Incorporation of Footing Drain Flows}

The SWMM R, T, and K parameters are used to model the RDII entering the sewer system. Greater detail in the use of these parameters is given in a separate chapter (Sherman et. al.)

Then the results of the hydrologic simulation from RUNOFF are used as input to the hydraulic model in EXTRAN, which is used to route flows to the WWTP and identify system constraints.

The City requires a model that will allow it to plan improvements and run simulations in support of the ongoing FDD Program. As footing drains are disconnected, the amount of RDII entering the sanitary sewer will be reduced. Therefore, in order for the model to be able to track progress of the FDD program, the approximately 50 RDII analysis areas were further broken into over 2,600 model sub-basins, with 10-15 houses per sub-basin. As each of the sub-basins have been assigned their own SWMM RTK volume and shape parameters, city engineers can adjust them to reduce the modeled amount of RDII entering the system at the sub-basin level as FDD progresses.

One other key aspect of the model is that it is setup to select either Growth (summer) or Dormant (winter) RTK volume and shape parameters.

\subsubsection{Pilot Model Development}

The project team developed a pilot model to test methods tailored specifically to the City's needs. The pilot model drew on the following information:

- Footing Drain Flow Contribution - Footing drain data were obtained from key areas in the collection system and used to help allocate wet and dry weather flows.

- Footing Drain Disconnection - The City's plan to reduce sanitary sewer overflows calls for the disconnection of footing drains. The pilot model was configured so it could help plan future disconnections and reflect them as they occur.

- Sewer Billing Data - Sewer billing data was applied at the parcel level. While there were some gaps and discrepancies in the data, the overall condition of the data was good enough to confirm the project team's metering estimates for dry weather flow. 
Further, the pilot model provided project staff a preview of methods proposed and better allowed improvements to be identified prior to the performing the work for the entire city.

\subsubsection{Hydraulic Model- EXTRAN}

The collection system GIS data were used to create the conduits and nodes for the model with some adjustments made to control modeling instabilities.

Model equivalencies were one option required to prevent instabilities. Volume and flow capacities were typically the same as the physical volume and flow capacities of the actual structures. However, in some cases, the modeled equivalency has a higher volume than is actually physically in the system. The amount of volume added from these equivalencies increases the total collection system volume by approximately 0.05 percent.

At some manholes, a small amount of additional storage is used to prevent numerical instability that sometimes occurs during model calculations under certain circumstances. The amount of additional storage added represents approximately $0.15 \%$ of the collection system full-pipe volume. This quantity has a negligible effect on model results.

The initial conduit flows were set to a small default value to control some initial instabilities prior to achieving steady state DWF (DWF modeled as a constant value).

During calibration, hydraulic grade line (HGL) was adjusted by considering Manning's "n", local losses and sediment buildup. The initial values used were 0.013 , but as part of the level calibration where increased to 0.015 . The values for "entrance and exit losses" were determined during model calibration and did not originate in the GIS. The City has a regular schedule for cleaning the system sewers. Nevertheless, the project team added a $5 \%$ sediment buildup in the model conduits to represent sediment in the collection system. The decision was based on calibration simulations that suggested the presence of sediments.

The model assumes that all pumps included operate at a constant rate. Pumps at the WWTP were not modeled. Instead, the downstream boundary condition was set as a free discharge from a single conduit representing the inlet to the WWTP.

The storage structures modeled include wet wells, junction chambers, and storage facilities or portions thereof. Details of each storage structure are based on as-built drawing information.

The model does not explicitly include the sewer hydraulics of suburban collection systems. Therefore, the model does not hydraulically route flows 
through each suburban customer's collections system. Instead, their dry weather flows, based on the flow metering or water uses information, are added as a constant flow input at their connection to the City's collection system. Furthermore, the wet weather response from these areas is accounted for using the RTK shape parameters identified for each individual area. Therefore, the RTK shape parameters implicitly account for routing through each suburban community's collection system.

DWF is represented as constant inflow to nodes as part of the hydraulic model. A single DWF inflow node was selected for each of the more than 2,600 model sub-basins as a means for providing a reasonable representation of the source of these flows. DWF factors were established to allow the model to be toggled between an average DWF or the peak of the diurnal for use as this constant input.

As part of the RDII analysis, flow meter data was used to find the average DWF for each of the approximately 50 RDII analysis areas by month. As DWF varies between the Dormant (winter) and Growth (summer) seasons, April DWF was used for the Dormant season and August DWF was used for the Growth season. These DWF values were then allocated to the more than 2,600 sub-basins by using information on sewage billing records, tributary area, and footing drain equivalents for each sub-basin. When sewage billing records were missing or inaccurate, the sanitary sewage component was estimated.

One key aspect of the allocation was to break the DWF for each subbasin into its two components: sanitary sewage and DWI/I. The DWI/I component is most important for project purposes because it can be linked to footing drain equivalents and adjusted as footing drain disconnection work proceeds.

\subsubsection{Hydrologic Model- RUNOFF}

Sub-basins were defined as part of the GIS development. The work was done in as consistent a manner as possible to ensure hydrology and dry weather flow allocation could be performed consistently.

There are larger sub-basins in some commercial/industrial areas, the Scio and Ann Arbor townships, and mixed residential and commercial/industrial areas. These large sub-basins were delineated more coarsely.

Some relatively small sub-basins were created due to the distinct nature of certain parcels. Nevertheless, $88 \%$ of the sub-basins were between 1 and 10 acres in size, as Table 4.1 shows. This consistency in sizing of the 
subbasins is one important factor in the ability to minimize the number of shape parameter sets required for the model.

Table 4.1 - Size distribution of sub-basins.

\begin{tabular}{ll}
\hline Area Ranges (acres) & Count \\
\hline Less than 1 & 37 \\
Between 1 and 10 & 2352 \\
Between 10 and 100 & 270 \\
Between 100 and 1,000 & 9 \\
Greater than 1,000 & 2 \\
\hline Total & 2670 \\
\hline
\end{tabular}

\section{Volume Parameters}

Volume parameters determined through RDII analysis of the flow monitoring data are input as for Dormant and Growth conditions. Each subbasin is allocated response volume as originating from non-footing drain sources or from both footing drain and non-footing drain sources. Each subbasin has a minimum response attributable to sources other than footing drains (FD). This value varies from 1.2 percent for the Growth season to 2.0 percent for the Dormant season. These values were determined from baselines established on a response versus percentage of footing drain plots of all project-metering areas.

Further, each sub-basin has a maximum response attributable to footing drains. This value is 300 cubic feet per inch of rainfall per FD equivalent. It was selected from the knee of the curve of $268 \mathrm{FD}$ monitoring points and is the point below which $94 \%$ of all data fall. Greater detail on the observed footing drain variability is given in a separate chapter (Sherman et. al.). In cases where the maximum FD response is exceeded by the meter-determined volume, the remainder of the response is assigned to the non-FD sources. The contributions of footing drains from commercial/industrial structures were determined to be negligible based on a separate study performed in one area of the city, and were not included.

Splitting of volume to the component hydrographs was done as part of calibration. Once the Dormant season splits were determined, the Growth season parameters were set by first assigning Growth season volume to the inflow hydrograph up to a maximum volume of that used for Dormant season inflow, with the remainder being assigned to the infiltration 
component hydrograph. If the Growth season's total response was less than that of the Dormant inflow volume, the entire Growth season response was assigned to the inflow component hydrograph.

\section{Shape Parameters}

Individual shape parameters are required for each rain gauge. There are 123 rainfall input sets for the model based on $1 \mathrm{~km} \times 1 \mathrm{~km}$ radar precipitation data "pixels." Couple this with the individual incremental metering areas requiring the flexibility of providing unique shape parameters and the fact that most incremental meter areas have both footing drain and non-footing drain areas that also require the flexibility of having shape parameter input, and the result is a total of 384 grouping levels for shape parameters that are included in the model input. However, as mentioned earlier in this chapter the shape parameters are comprised of only six sets.

\section{Inflow Nodes}

Inflow nodes were selected in a systematic manner based on the following factors:

- Flow should not be assigned to a pipe through which that flow never actually passes.

- Preference is given to the nodes within the downstream half of a subbasin, not necessarily sewer reach length. This helps minimize chances of loading too much flow upstream in the case of a pipecapacity transition within a sub-basin's sewer reach.

There were some limitations to this method. For example, most of the conduits far upstream received no loadings of dry or wet weather flow. Future evaluations of the upstream portions of the sewer should consider the benefits of loading some inflow at the points farthest upstream.

\section{Rainfall Allocation}

Each sub-basin was assigned one radar pixel (1 km x $1 \mathrm{~km}$ spatial unit) as its rainfall input. The pixel selected for a given sub-basin was the one with the greatest area within that sub-basin as determined by a GIS intersection of the two layers. As a result, 123 radar pixels' rainfall volumes were used in the calibration and validation of the citywide model. Rainfall data input for all simulations was provided at five-minute intervals. 


\subsubsection{Model Calibration and Validation}

Model calibration and validation began with the selection of storm events that would help refine model parameters. This step also included quality assurance and quality control (QA/QC) checks of the data and results. A standard method was established to calibrate the shape parameters in groups, instead of individually for each incremental meter area. The calibration goals for volume were set at $10 \%$ error and peak flows at $20 \%$. These goals were met.

\section{Event Selection}

The monitoring period between April and September 2003 did not yield any large events that significantly stressed the collection system. Such events would have been quite useful in calibrating the model. However, the events that did occur were selected for the following traits:

- complete flow/level data;

- system responses that reflect the Dormant and Growth seasons; and

- $\quad$ size (the largest events being favored).

The model was calibrated to the Dormant season using the April 3-7, 2003, storm event. It was calibrated to the Growth season using the May 2831,2003 , storm event. In addition, the model was validated to the Dormant season during a May 5, 2003 storm event. It was validated to the Growth season during an August 21, 2003 storm event.

\section{Model Input $Q A / Q C$}

QA/QC of model input was an integral part of the calibration process. This included checking DWF and RDII input, which were both revisited to confirm their affect on the overall model. Further, the collection system was examined ecarefully to verify that the representation of the system hydraulics did not include errors that might heighten observed problems. In a few key locations, the initial model was found to be inadequate.

The preliminary calibration $\mathrm{QA} / \mathrm{QC}$ also included efforts to resolve simulation-related errors. Test simulations based on a large stress event were run at key intervals during the model development and preliminary calibration. This allowed early stress testing to identify and resolve numerical instabilities. With these numerical instabilities addressed, 
remedies such as equivalent hydraulics and additional storage were added to the calibration.

Once the majority of the preliminary calibration work was performed and a baseline model was nearly complete, the project team performed a detailed profile evaluation. This evaluation, also based on the stress event, was performed at the same time as the calibration. Nearly every model profile was examined to identify and correct problems not previously identified. In particular, the project team investigated pipe crossings, complex junctions, suspected problems with elevations and diameters, surcharged pipes, and instabilities. The team also performed numerous random checks of manhole depths.

\section{Methods}

Due to the model's large scale, the calibration first assessed critical input values and parameters. This preliminary calibration also evaluated the adequacy of estimates used for DWF and RDII input. For example, the RDII volume balance used as input to the allocation of wet weather parameters was critiqued in the context of its overall influence within the model framework. In a number of cases, RDII analysis results were refined based on this evaluation. DWF input was similarly evaluated.

As part of the preliminary calibration, the methods of assigning the $\mathrm{C} 1$ :C3 component hydrograph split (the split of total $\mathrm{R}$ ) and the $\mathrm{T}$ and $\mathrm{K}$ shape parameters were evaluated. This assessment led to a decision to limit the $\mathrm{T}$ and $\mathrm{K}$ variability to a small number of groups and focused more on allowing $\mathrm{C} 1$ : $\mathrm{C} 3$ to vary to account for more detail in the shape differences. It was also determined that $\mathrm{C} 1$ could remain, for the most part, fixed between seasons, with most of the seasonal variability attributed to the infiltration component hydrograph. Approximately 10 percent of the sub-basins do not retain full Dormant season inflow response volume when switching to Growth season conditions.

While performing these checks, volume and peak flow differences between measured and simulated hydrographs were the objective functions considered. Points of comparison were the metering locations and the WWTP total influent flow. Secondary to this was consideration of HGL at the metering locations, and to a limited extent from the peak stage recorder data. This evaluation led to two conclusions: first, minor losses needed to be increased throughout the model; and second, small amounts of sediment needed to be included. 
Once the general input values were refined, and allocation and grouping of model parameters were determined, the simulation calibration events were finalized though minor changes to the $\mathrm{T}$ and $\mathrm{K}$ values and the $\mathrm{C} 1: \mathrm{C} 3$ splits.

For validation, the model was used to compute event responses for events not included in its calibration.

Results

Tables 4.2 and 4.3 list the calibrated shape parameters for the base line models.

Table 4.2 - Fraction of volume assigned to inflow component of response hydrograph (C1:C3 split).

\begin{tabular}{llcc}
\hline Areas Affected & \multicolumn{2}{l}{ Footing Drains } & \multicolumn{2}{c}{$\begin{array}{c}\text { Percent of } \\
\text { Volume to } \\
\text { Inflow* }\end{array}$} \\
\hline $\begin{array}{l}\text { General Application } \\
\text { (except specific areas noted below) }\end{array}$ & No & & $20 \%$ \\
$\begin{array}{l}\text { General Application } \\
\text { (except specific areas noted below) }\end{array}$ & & $\mathrm{x}$ & $15 \%$ \\
03A, 04C, 05A, 11A & & & \\
06A, 07A, 08B, 09A, 09B & $\mathrm{x}$ & & $30 \%$ \\
08A & $\mathrm{x}$ & & $15 \%$ \\
13A & $\mathrm{x}$ & & $40 \%$ \\
06A, 07A, 08B, 09A, 09B & $\mathrm{x}$ & $\mathrm{x}$ & $50 \%$ \\
\hline
\end{tabular}

*Values shown represent dormant season. Growing season maintains the volume to inflow of the dormant season while reducing infiltration accordingly. If the overall growing response was less than that of the dormant season inflow, then the inflow was reduced accordingly and infiltration was set to zero.

In the case of four flow meters, no discernable RDII volume or peak was found in the data, so no calibration comparison is available. No RDII analysis was performed on these meters, and low $\mathrm{R}$ values were assigned.

For volume comparisons, event-specific $\mathrm{R}$ values may be significantly higher or lower than the average regressed $\mathrm{R}$ value set in the model. For example, when a RDII volume for a given meter and event is higher than the average RDII regression line found during the RDII analysis, the model will under compute volumes. Thus, the spread of event-specific volumes around 
the average regressed RDII $\mathrm{R}$ value accounts for most of the variation between model and observed volumes.

Table 4.3 - T and K RDIl shape parameters.

\begin{tabular}{|c|c|c|c|c|c|c|}
\hline \multirow[t]{2}{*}{ Areas Affected } & \multicolumn{2}{|c|}{$\begin{array}{c}\text { Footing } \\
\text { Drains }\end{array}$} & \multicolumn{4}{|c|}{ Component Hydrograph Shape Parameters* } \\
\hline & Yes & No & $\mathrm{T} 1$ & K1 & $\mathrm{T} 3$ & K3 \\
\hline $\begin{array}{l}\text { General Application } \\
\text { (except specific areas } \\
\text { noted below) }\end{array}$ & $\mathrm{x}$ & & 2 & 1.4 & 5 & 18.2 \\
\hline $\begin{array}{l}\text { General Application } \\
\text { (except specific areas } \\
\text { noted below) }\end{array}$ & & $\mathrm{x}$ & 2.4 & 1 & 5 & 18.2 \\
\hline $03 \mathrm{~B}, 17 \mathrm{C}$ & $\mathrm{x}$ & $\mathrm{x}$ & 1.2 & 1 & 5 & 18.2 \\
\hline $06 \mathrm{~A}$ & $\mathrm{x}$ & $\mathrm{x}$ & 5 & 1 & 10 & 8.6 \\
\hline 07A, 07B, 09D & $\mathrm{x}$ & $\mathrm{x}$ & 3 & 1 & 5 & 18.2 \\
\hline $13 \mathrm{~A}$ & $\mathrm{x}$ & $\mathrm{x}$ & 2 & 2 & 8 & 3 \\
\hline
\end{tabular}

*Apply to both dormant and growing seasons

Some variation also occurs when estimated $\mathrm{R}$ values are used. On average, the model computes volume within $15 \%$ of the actual volume for each meter (with two exceptions) and within 3.5\% overall using a weighted average. At the WWTP, the computed volume is within $1 \%$ of the volume observed.

To evaluate the affects of shape parameters on peak flows, peak flow comparisons include an adjustment for the percent difference between model and observed volumes. On average, the model computes peaks within $20 \%$ for each meter and within $1.3 \%$ overall using a weighted average. At the WWTP, the volume checks are within five percent of the volume observed. In general, most model peaks are also within $20 \%$ of each event.

In addition to providing a sound and stable baseline model, the calibration and validation produced other significant results. Specifically, they demonstrated that:

- Consistently delineated sub-basins made defining shape parameters much easier. Minimizing variation in sub-basin sizing and keeping the subbasins small so as to minimize routing variation influence resulted in the need for only a small group of differing $\mathrm{T}, \mathrm{K}$, and $\mathrm{C} 1: \mathrm{C} 3$ split parameters. 
- The inflow response tended to be similar per unit of rainfall from Dormant to Growth season, with the majority of the volume difference attributed to reduced infiltration during the Growth season.

- Peak flow at the WWTP appeared to be attenuated adequately based on routing and comparison with the observed peak flows at meters upstream from the plant.

- HGLs found to be low when model results were compared to actual HGLs suggested an increase in entrance/exit losses, Manning's "n," and sediment depth.

- There is good overall correspondence among measured peaks and volumes and simulated peaks and volumes.

- Parameters defined during calibration performed well during other events.

\subsection{Conclusions}

The citywide model has several important functions. It can be used to prioritize areas for footing drain removal to minimize FD flows and relieve system deficiencies and basement flooding. The model can also help to evaluate proposed development projects by analyzing available capacity and identifying locations for FD mitigation to offset new development. Further, it can assist in the review of system upgrade alternatives. Thus it supports development where FD mitigation will not resolve system problems.

The Citywide Monitoring and GIS Project generated a number of insights that were incorporated into the model:

- Water use records can be used to determine expected dry weather flows throughout the collection system.

- The response of the collection system varies by season. During the Dormant season, response volume was significantly greater than during the Growth season. The transition between seasons takes place in mid-May for the 2003 monitoring year. This seasonal response was consistent with previous monitoring work performed in 2000.

- Area models are not required. Simulations suggested the model should be constructed as one contiguous entity, rather than as separate area models. One model greatly simplifies future modeling activities and information management. 
- Footing drains generate significant RDII. Areas containing footing drains responded to rainfall quite differently than areas without footing drains. This finding was expected and verified through previous monitoring and modeling work.

- Structure age affects response by footing drains. Flow monitoring showed that structures constructed between 1945 and 1982 generate significantly more flow than structures constructed before 1945 . This may be related to the efficiency of the footing drains or absence thereof.

- Soil type affects footing-drain response as well. Structures located in clay soils produce more volume and higher inflow than those in sandy soils.

- Two response hydrographs adequately represent the system's response. While the SWMM model can handle three separate response hydrographs, the calibration work showed that two adequately simulated the system's behavior. The two hydrographs are used to simulate inflow (immediate response) and infiltration (delayed response).

- Inflow and infiltration timing is consistent. Although the timing of the inflow and infiltration hydrographs could have been calibrated independently for each metered area, it was found that only six different groupings of parameters were required to define the response time to peak and hydrograph recession time for the inflow hydrograph and a separate set for the infiltration hydrograph.

- While response volume changes by season, the volume of inflow does not change by season for $90 \%$ of the collection system. Of the remaining $10 \%$, the total volume produced during the growing season is less than the dormant season inflow-only component.

It is also important to understand the model's key limitations so it can be used properly. First, the hydraulic model is based on GIS and attribute information. In general, these data are of excellent quality but likely include some errors. Second, the definition of 2,600 hydrologic sub-basins incorporates assumptions about average footing drain rates and sanitary billing data that may actually vary from location to location. There are likely local deviations for which the model does not account. Third, the citywide model is based on monitoring data that, though rigorously reviewed, likely contains errors as well. Fourth, system response factors may deviate significantly depending on antecedent soil conditions and rainfall intensities. Finally, it should be noted that even though the model may be used for 
continuous simulations, there are parameters that would need to be calibrated before doing so.

Because of these limitations, results for flow, level, and volume will contain some uncertainty. The calibration goals for volume were set at 10 percent error and peak flows at $20 \%$. These goals were met. Therefore, all work that depends on these model simulations should include safety factors to account for these uncertainties. When higher levels of accuracy are needed, it may be worthwhile to perform additional local monitoring to validate or better define model parameters.

\section{References}

Sanitary Sewer Overflow Study Task Force, Report to City of Ann Arbor City Council, http://www.cdm-mich.com/aa-sso/FinalReport.htm, SSO Prevention Study - Final Report, June 2001.

Schultz N.U.,Wood D.M., Adderly V., and Bennett D., 2001. RDI/I Quanitifcation Research Results, Conference Proceedings of the $4^{\text {th }}$ DHI Software Conference \& DHI Software Courses, Helsingør, Denmark, 6-8 June 2001.

Sherman, B. J., C. Rolfe, P. P. Perala, C. Hupy, M. J. TenBroek, "Implementing SSO Control - Technical Aspects", Proceedings of the Water Environment Federation WEFTEC 2002 Conference. Chicago, IL. October 2002.

Sherman, B.J., P.P. Perala, M.C. Stonehouse, H. Fan and M.J. TenBroek. 2005. "Allocating RDII Using Footing Drain Flow and Other Information." Journal of Water Management Modeling R225-21. doi: 10.14796/JWMM.R225-21.

Zawacki, J. R., I. Kotlyar, B. J. Sherman, M. J. TenBroek, "Effective I/I Removal with Footing Drain Disconnection as a Solution for SSO and Basement Flooding", Alternate Paper, 2005 WEF Collection Systems Conference - Sustaining Aging Infrastructure: System, Workforce, and Funding. Boston, MA. July 17-20, 2005. 
